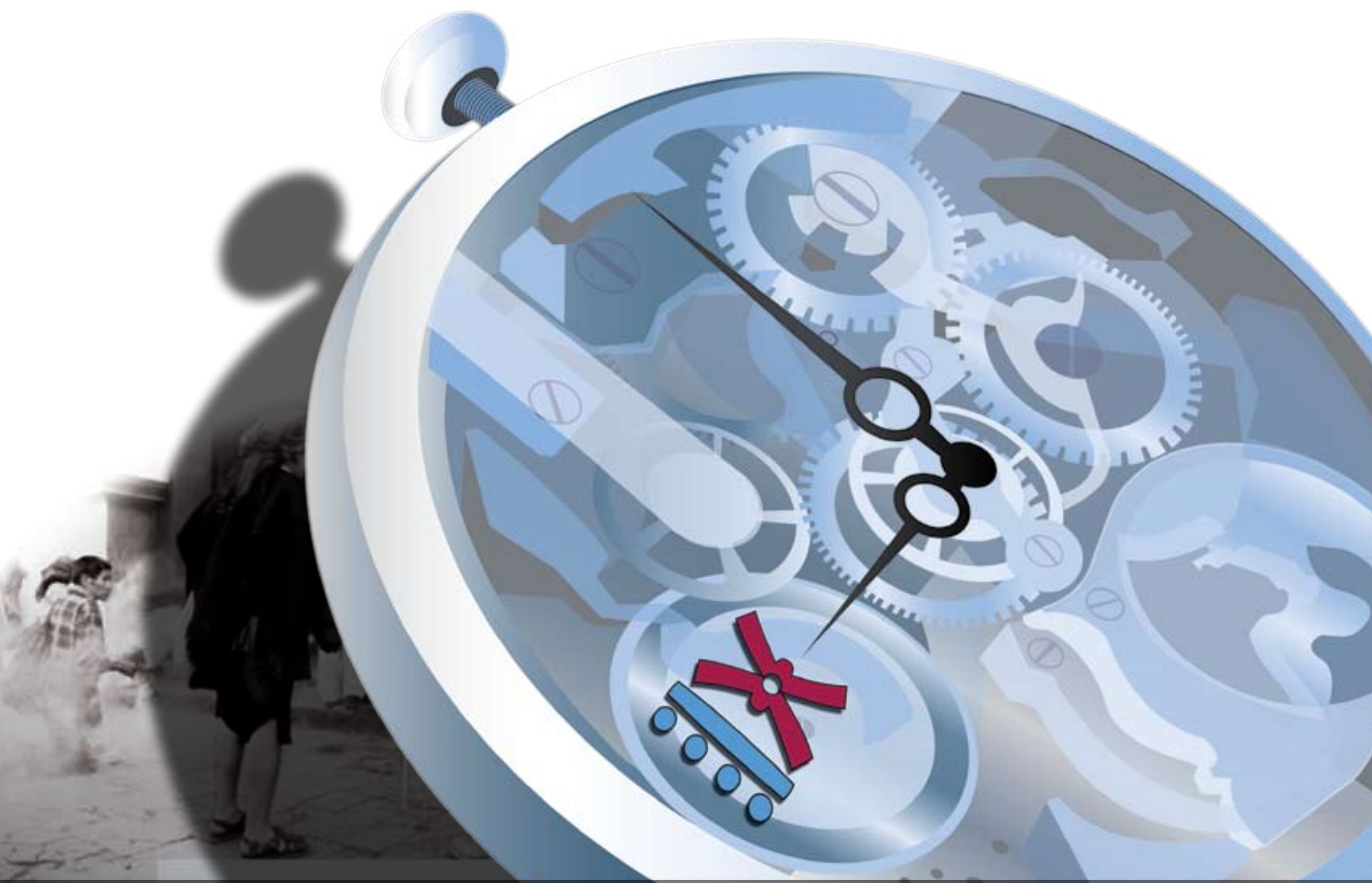

\section{$9^{\circ}$ C O N G R E S O 2. CENTROAMERICANO DE H IS TO R I A}

ISSN 1409-469X

Fecha de recepción: 15 de mayo 2008 Fecha de aceptación: 30 de mayo 2008

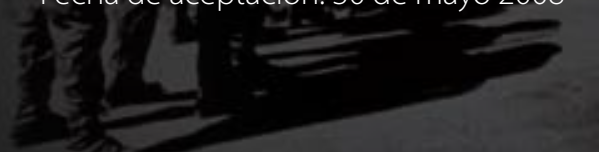

Sexo, mentiras y documentos de archivo: un episodio del siglo XVII con una advertencia a todos los historiadores

Miembros del Consejo Editorial:

Dr. Ronny Viales, Dr. Juan José Marín

Editores Técnicos:

Allan Fonseca, Andrés Cruz, Gabriela Soto

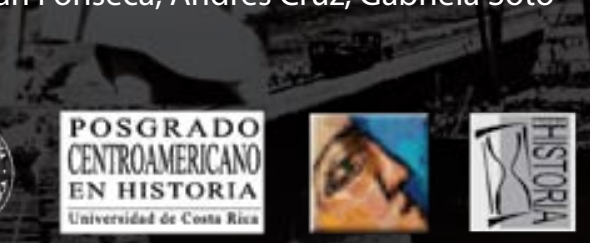




\title{
Sexo, mentiras y documentos de archivo: un episodio del siglo XVII con una advertencia a todos los historiadores
}

\author{
por STEPHEN WEBRE \\ Louisiana Tech University
}

El 13 de julio de 1672, don José de Calatayud y Castillo, capitán de infantería avecindado en La Habana, pidió a un escribano que le sacara un poder. ${ }^{1}$ Oriundo de Santiago de Guatemala, después de su llegada en el puerto cubano hacía unos siete años Calatayud se había casado con una mujer de buena familia y para reforzar sus pretensiones de nobleza estaba solicitando ingreso como caballero de la Orden de Santiago. A primera vista, no había de existir impedimento alguno a tal pretensión. El padre difunto del capitán, don Antonio de Calatayud y Sandoval, había servido a la monarquía en muchas capacidades, como lo habían hecho también varios de sus parientes. Por el lado de su madre, doña Bárbara del Castillo, don José era descendiente de conquistadores y en particular de Bernal Díaz del Castillo, renombrado veterano e historiador de la conquista de la Nueva España. ${ }^{2}$ Por lo tanto, Calatayud contaba entre sus parientes algunas de las familias más influyentes de la provincia de Guatemala.

Sin embargo de este linaje al parecer ilustre, el capitán don José de Calatayud tenía dos problemas. Primero, a pesar de su alta posición social, sus padres no estaban casados. En una sociedad cuyo sistema de valoración social se basaba en el concepto del honor, la ilegitimidad

El autor es titular de la cátedra de historia W. Y. Thompson y director del Departamento de Historia de la Louisiana Tech University, Ruston, La., EE.UU. Agradece la colaboración y ayuda de Alfredo Castillero Calvo, Margaret y Sean Hogg, Matthew Hovious, Christopher H. Lutz, Murdo J. MacLeod y Anthony S. Pasinski. Reconoce asimismo el aporte financiero de la cátedra Thompson y del fondo Garnie W. McGinty del mismo departamento. Los comentarios y preguntas pueden dirigírsele a swebre@latech.edu

${ }^{1}$ Exp. d. José de Calatayud y Castillo, 1672, Madrid, Archivo Histórico Nacional (en adelante AHN), Ordenes Militares, expedientillos 4264.

${ }^{2}$ Herbert Cerwin, Bernal Díaz, Historian of the Conquest (Norman: University of Oklahoma Press, 1963), sigue siendo la biografía más frecuentemente citada. Sobre la genealogía de los Castillo de Guatemala, el mejor trabajo es, de Edgar Juan Aparicio y Aparicio, marqués de Vistabella, Bernal Díaz del Castillo y sus descendientes (México: Tipografíá Guadalajara, 1969). 
podía considerarse como una mancha tanto para la madre como para el hijo. ${ }^{3}$ Sin embargo, era una mancha cuyo efecto podía variar mucho según las circunstancias del caso. En el que nos ocupa, a excepción de no participar en la herencia de los bienes dejados con la muerte de su padre, existe poca evidencia de desventajas sociales padecidas por don José de Calatayud con motivo de su origen ilegítimo. El mismo no constituía forzosamente un obstáculo para su recepción en la Orden de Santiago, pero sí lo hacía necesario proceder cautelosamente al gestionar la extensiva investigación de sus antecedentes genealógicos a que había de someterse antes de ser admitido como caballero.

El otro problema de don José era que sus responsabilidades militares no permitían que se ausentara de Cuba para tramitar su solicitud personalmente. Fue por este motivo que sacó el poder en 1672, en que le autorizaba para el citado efecto a su cuñado, don Gregorio Altamirano Portocarrero, miembro del Consejo de Hacienda en Madrid, y a dos otras personas también residentes en esa corte. ${ }^{4}$ No existe documento alguno que nos demuestre exactamente lo que hicieran Altamirano y sus colaboradores para facilitar el ingreso de Calatayud como caballero de Santiago, pero el resultado visible de sus esfuerzos es un legado documental caracterizado por omisiones, mentiras y falsificaciones. En breve, se trata de una especie de "verdad notarial”, en que se emplea la escritura para reducir la realidad compleja y desordenada, reemplazándola con una versión limpia y concisa, que aunque incompleta y errónea, es suficiente para el logro del fin a que se destina. ${ }^{5}$ En el caso de don José de Calatayud y Castillo, la red de falsedades tejida alrededor de su persona y origen quedó sin detectar-o si es que fue detectada, sin revelar públicamente-aprobándose sin dificultad su solicitud de ingresar en la Orden de Santiago. Porque no hay motivo de pensar que este caso fuera único en su época, la historia de don José de Calatayud y las mentiras que de su cuenta se perpetuaron constituye una advertencia a todos los

\footnotetext{
${ }^{3}$ Para una introducción al sistema de honor, véase de Julian Pitt-Rivers, The Fate of Shechem, or the Politics of Sex: Essays in the Anthropology of the Mediterranean (Cambridge: Cambridge University Press, 1977). La relación entre el honor y el status social en la España del siglo XVII es examinada por Antonio Maravall, en Poder, honor y élites en el siglo XVII (Madrid: Siglo XXI, 1979). Sobre el sistema y su funcionamiento en las provincias ultramarinas ibéricas, es recomendable Faces of Honor: Sex, Shame, and Violence in Colonial Latin America, coord. de Lyman L. Johnson y Sonya Lipsett-Rivera (Albuquerque: University of New Mexico Press, 1998). Para la historia de la ilegitimidad, véase Bastardy and its Comparative History: Studies in the History of Illegitimacy and Marital Nonconformism in Britain, France, Germany, Sweden, North America, Jamaica, and Japan, coord. de Peter Laslett, Karla Oosterven, and Richard M. Smith (Cambridge: Harvard University Press, 1980). El mejor trabajo sobre el caso latinoamericano es de Ann Twinam, Public Lives, Private Secrets: Gender, Honor, Sexuality, and Illegitimacy in Colonial Spanish America (Stanford: Stanford University Press, 1999).

${ }^{4}$ Exp. d. José de Calatayud y Castillo, 1672, AHN, Ordenes Militares, expedientillos 4264.

5 Para el concepto de la "verdad notarial”, véase de Kathryn Burns, "Notaries, Truth, and Consequences", American Historical Review, CX, núm. 2 (abril de 2005), 350-379.
} 
historiadores, recordándonos que los seres humanos de carne y hueso quienes produjeron los documentos escritos de que dependemos tan pesadamente, lo hicieron para sus fines particulares y de ninguna manera para los nuestros. ${ }^{6}$

Nació don José de Calatayud y Castillo en Guatemala en marzo o abril de 1626. Su madre, una viuda joven y rica de nombre de doña Bárbara del Castillo (1603-1677), era la hija más grande de Pedro del Castillo Becerra, hijo segundo de Bernal Díaz del Castillo y Teresa Becerra. $^{7}$ En 1624, poco después de fallecer inesperadamente su primer esposo, el comerciante español Tomás Meléndez, doña Bárbara tuvo la que en aquella época se llamaba una "amistad ilícita” con don Antonio de Calatayud y Sandoval (1590-1663), recientemente llegado como oidor de la audiencia de Guatemala. De la citada unión fueron nacidos dos hijos ilegítimos, de los cuales don José era el menor. ${ }^{8}$ La relación entre doña Bárbara y don Antonio parece haber terminado al final de 1627 o a principios de 1628, con la llegada en Guatemala de doña María Magdalena de Castro, a quien el oidor recibió diciendo que era su esposa. Procedente de Guayaquil, doña María Magdalena fue hija del influyente comerciante y constructor de navíos Toribio de Castro Guzmán, a quién Calatayud conocía desde el tiempo en que había desempeñado como corregidor de Riobamba en la audiencia de Quito. La joven Castro tenía solamente doce años, pero según los cánones vigentes eso era suficiente para la consumación de

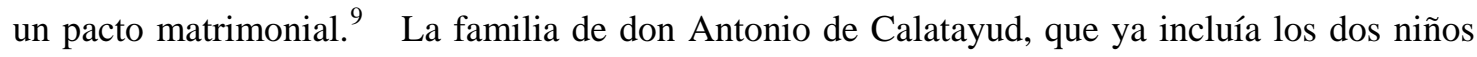
procreados con su amante doña Bárbara del Castillo, ahora fue aumentada por el nacimiento de dos hijas legítimas por doña María Magdalena de Castro, la cual murió poco después, posiblemente víctima de la epidemia que brotó en Santiago en $1631 .{ }^{10}$ En 1633, habiendo sido nombrado oidor de la audiencia de Charcas, Calatayud se marchó de Guatemala, llevando

\footnotetext{
${ }^{6}$ Siempre se han dado cuenta de esto los mejores historiadores, aunque sean pocos los que lo han dicho explícitamente. Además de Burns, “Notaries, Truth, and Consequences”, otro estudio que versa directamente sobre esta cuestión es, de Natalie Zemon Davis, Fiction in the Archives: Pardon Tales and their Tellers in SixteenthCentury France (Stanford: Stanford University Press, 1987).

${ }^{7}$ Aparicio, Bernal Díaz, 25-26.

${ }^{8}$ Exp. d. José de Calatayud y Castillo, 1674, AHN, Ordenes Militares 1385, fol. 15.

${ }^{9}$ Calatayud a la corona, Guatemala, 4 de mayo de 1624, Sevilla, Archivo General de Indias (en adelante AGI), Guatemala 15, ramo 3, núm. 16; exp. d. José de Calatayud y Castillo, 1674, AHN, Ordenes Militares 1385, fol. 15v. Sobre la familia Castro en Guayaquil durante el siglo XVII, véase de Lawrence A. Clayton, Caulkers and Carpenters in a New World: The Shipyards of Colonial Guayaquil, Papers in International Studies, Latin America Series, núm. 8 (Athens: Ohio University Center for International Studies, 1980), 141-157.

${ }^{10}$ Exp. d. José de Calatayud y Castillo, 1674, AHN, Ordenes Militares 1385, fol. 2v; Antigua Guatemala: cronología guatemalteca del siglo XVII: memorias del M.R.P. maestro fray Antonio de Molina continuadas y marginadas por fray Agustín Cano y fray Francisco Ximénez, de la orden de Santo Domingo, ed. de Jorge del Valle Matheu (Guatemala: Unión Tipográfica, 1943), 24-25.
} 
consigo tanto a las dos niñas como a los dos varones que tuvo con doña Bárbara del Castillo. ${ }^{11}$ No consta la actitud de doña Bárbara ante esta separación de sus únicos hijos, pero lo que sí es cierto es que jamás los volvió a ver.

Bajo una construcción estricta del código de honor, el hecho de la ilegitimidad debía de haber constituido una mancha en las reputaciones tanto de don José de Calatayud como de su madre doña Bárbara del Castillo. Sin embargo, la realidad hispanoamericana del siglo XVII parece haber sido más compleja que lo que comúnmente se cree, existiendo muchos variables que podían mitigar los efectos de los hechos vergonzosos. Por ejemplo, sin importar qué valores fueran sostenidos por la iglesia o por la monarquía, hay evidencia abundante para sugerir que aun entre las élites, el matrimonio estaba lejos de ser el contexto universal de la procreación. ${ }^{12}$ En Santiago de Guatemala, por ejemplo, durante la década del 1640 los nacimientos ilegítimos representaron el 40 por ciento de los bautizos de niños españoles y más del 75 por ciento de los bautizos de niños de raza mezclada (“castas” o "gente ordinaria”). ${ }^{13}$ En todo caso, si doña Bárbara del Castillo se desviaba de las normas de conducta sexual que se consideraban apropiadas a una mujer de su clase social, sus iguales justificaban ese comportamiento bajo el pretexto de que el oidor Calatayud le había prometido matrimonio y que fue solamente como consecuencia de dicha promesa que doña Bárbara había aceptado tener relaciones sexuales con él. $^{14}$

Por su parte, salvo en la cuestión de la herencia (como adelante se explicará) don José de Calatayud tampoco parece haber experimentado mayores desventajas sociales. Al menos en parte, esto se debió a que su padre era una persona de medios e influencia, quien no parecía

\footnotetext{
${ }^{11}$ Ernesto Schäfer, El Consejo real y supremo de Indias: su historia, organización y labor administrative hasta la terminación de la Casa de Austria, 2 tomos (Sevilla: Universidad de Sevilla, Publicaciones del Centro de Estudios de Historia de América, 1935; Sevilla: Escuela de Estudios Hispanoamericanos, 1947), II, 507; exp. d. José de Calatayud y Castillo, 1674, AHN, Ordenes Militares 1385, fol. 12.

12 Sobre esta cuestión véase, de María Emma Mannarelli, Pecados públicos: la ilegitimidad en Lima, siglo XVII (Lima: Ediciones Flora Tristán, 1993), en que se describe una realidad limeña del siglo XVII que parece haber tenido mucho en común con la de Guatemala en la misma época.

${ }^{13}$ Christopher H. Lutz, Santiago de Guatemala, 1541-1773: City, Caste, and the Colonial Experience (Norman: University of Oklahoma Press, 1994), 234.

${ }^{14}$ Esta versión de los eventos fue contada por la propia doña Bárbara del Castillo y fue repetida muchas veces por los testigos presentados por la parte de su hijo, don José de Calatayud. Exp. d. José de Calatayud y Castillo, 1674, AHN, Ordenes Militares 1385, fol. 15. Era común en esa época justificar las transgresiones sexuales con el pretexto de una supuesta promesa de matrimonio. Abigail Dyer, "Seduction by Promise of Marriage: Law, Sex, and Culture in Seventeenth-Century Spain”, Sixteenth Century Journal, XXXIV, núm. 2 (2003), 439-455.
} 
renuente de reconocerlo públicamente. ${ }^{15}$ También se debió a que existía generalmente la presuposición de que en el momento de su nacimiento, los padres de don José eran solteros, lo que significaba que aunque no estuvieran casados, no existía ningún impedimento que lo prohibiera. Según este criterio, el joven Calatayud pertenecía a una subcategoría específica de ilegítimos, la de los llamados “hijos naturales”. Aunque no se igualaran bajo la ley con los hijos de legítimo matrimonio, los hijos naturales no padecían de las mismas desventajas que afectaban a los “adulterinos” (hijos de adulterio), los “sacrílegos” (hijos de clérigos, religiosos o religiosas) o los “incestuosos” (hijos de padres emparentados dentro de los grados prohibidos). ${ }^{16}$ Para un hijo natural, el principal limitante tuvo que ver con los derechos de herencia, los que a diferencia del honor o la hidalguía, no se determinaban por la opinión pública sino por la ley. ${ }^{17}$

En los documentos relacionados a doña Bárbara del Castillo durante el período después de terminar su relación con el oidor don Antonio de Calatayud, no hay nada que indique una disminución de su posición en la jerarquía social santiagueño. La madre de don José de Calatayud permaneció en Guatemala, donde a pesar de las transgresiones de su juventud, recibía el tratamiento a que se acostumbraban las mujeres de la élite criolla. ${ }^{18}$ Se casó en segundo matrimonio con don Martín Alfonso de la Tovilla, soldado y administrador colonial quien había llegado en Guatemala desde España en 1630. Como pariente de los Tovilla y Mazariegos, familias prominentes que trazaban su ascendencia en Chiapas y Guatemala a la época de la conquista, don Martín gozaba de influencia y patrocinio político, como evidencia su ejercicio durante su carrera de un buen número de oficios públicos. ${ }^{19}$ Castillo y Tovilla no tuvieron hijos. Sin embargo, al fallecer éste en 1654 doña Bárbara se encontraba presidiendo sobre una casa principal y respetada, ubicada a unas dos cuadras de la plaza mayor y poblada por sirvientes y esclavas y en ocasión también por parientes, notablemente por una sobrina, el marido de ésta y

${ }^{15}$ Como lo hizo, por ejemplo, en las instrucciones que dio a su yerno don Gregorio Altamirano poco antes de su muerte en 1663. Actas de Isidro Núñez, 1663, Madrid, Archivo Histórico de Protocolos (en adelante AHPM), núm. 9541, fol. 678 .

${ }^{16}$ Twinam, Public Lives, 128.

${ }^{17}$ Sobre esta distinción importante, así como para la relación entre la ilegitimidad y la herencia, véase de Twinam, Public Lives, 216-240.

${ }^{18}$ Exp. d. José de Calatayud y Castillo, 1674, AHN, Ordenes Militares 1386, fol. 17.

${ }^{19}$ A Tovilla se le recuerda hoy en día por la relación que hizo de sus experiencias en la frontera guatemalteca. Véanse las Relaciones histórico descriptivas de la Verapaz, el Manché y Lacandón, en Guatemala, ed. de France V. Scholes y Eleanor B. Adams (Guatemala: Editorial Universitaria, 1960). También de Stephen Webre, "Spanish Failure on the Guatemalan Frontier: don Martín Alfonso de la Tovilla y la Relación de Verapaz y Manché, 16311635”, ponencia presentada ante la Latin American Studies Association, Montreal, Canadá, 4 a 8 de septiembre de 2007. 
sus ocho criaturas. ${ }^{20}$ Cuando doña Bárbara del Castillo murió en 1677 a la edad de setenta y tres años, fue sepultada en la iglesia de San Francisco en la misma capilla donde descansaban los restos del personaje espiritual más reverenciado de su época, Santo Hermano Pedro Betancourt $(1626-1667) .^{21}$

Como ya se apuntó, cuando todavía era niño don José de Calatayud fue llevado a Sudamérica, donde creció en casa de su padre, don Antonio de Calatayud, mientras éste desempeñaba primero como oidor de Charcas y luego como oidor de Lima. ${ }^{22}$ Llegando a la edad acostumbrada, se hizo soldado, prestando servicio en Filipinas y en Extremadura. ${ }^{23}$ En los últimos años de la década del cincuenta, don Antonio de Calatayud regresó a España, donde le esperaba un nombramiento al Consejo de Indias, en premio de sus muchos años de servicio en la administración colonial. ${ }^{24}$ Cayendo enfermo y con presentimiento de la muerte, en 1663 don Antonio encargó sus negocios a don Gregorio Altamirano Portocarrero, esposo de doña María de Calatayud y Castro, la mayor de las dos hijas de su matrimonio con doña María Magdalena de Castro. Al fallecer Calatayud, doña María heredó el mayorazgo familiar, el que incluía propiedades urbanas y rurales en Valladolid y su entorno, mientras que su hermana menor, doña Josefa de Calatayud, recibió una porción de los bienes que no estaban sujetos al mayorazgo. Bajo la ley, Calatayud tenía posibilidad de dejar hasta la quinta parte de sus bienes fuera del mayorazgo a sus "hijos naturales". Sin embargo, no lo hizo. Aunque reconociera abiertamente a don José de Calatayud y Castillo y a su hermano mayor, don Antonio de Calatayud y Castillo, como sus hijos habidos fuera de matrimonio con doña Bárbara del Castillo, el único legado que les dejó fue una instrucción a Altamirano que se los recomendara a la monarquía para que fueran favorecidos en recompensa por los servicios de su padre. ${ }^{25}$

Para don José el favor del rey no tardó mucho en presentarse en la forma del nombramiento como capitán de la guarnición de La Habana, el que recibió en 1665, así como de la concesión en el mismo año de un hábito, o plaza de caballero, en la Orden de Santiago. ${ }^{26}$

\footnotetext{
${ }^{20}$ Testamento, da. Bárbara del Castillo, 6 de marzo de 1676, Actas de Juan de Jerez Serrano, Guatemala, Archivo General de Centroamérica (en adelante AGCA), A1 .1477, fol. 24.

${ }^{21}$ Parroquia del Sagrario, Libro 2 de defunciones de españoles, parte 3, 1664-1698, fol. 67v, Guatemala, Archivo Histórico Arquidiocesano Francisco de Paula García Peláez (en adelante AHAG).

${ }^{22}$ Schäfer, Consejo real y supremo de Indias, II, 483.

${ }^{23}$ Nombramiento, d. José de Calatayud, 1665, AGI, Contratación 5789, lib. 2, fol. 363-365v.

${ }^{24}$ Exp. d. José de Calatayud y Castillo, 1674, AHN, Ordenes Militares 1385, fol. 8, 12v, 16v, 21.

${ }^{25}$ Poder para testar, d. Antonio de Calatayud y Sandoval, 10 de septiembre de 1663, Actas de Isidro Núñez, 1663, AHPM, núm. 9541, fol. 677-678v.

${ }^{26}$ Exp. d. José de Calatayud y Castillo, 1672, AHN, Ordenes Militares, expedientillos 4624.
} 
Como las otras órdenes militares de Alcántara y Calatrava, la de Santiago trazaba su fundación al siglo XII, a partir de cuyo momento desempeñó un papel importante en las guerras de la Reconquista. Cinco siglos más tarde, la orden había perdido tanto su función militar como su autonomía feudal, pero los hábitos de caballero seguían siendo codiciados por el prestigio social que llevaban, especialmente para familias recién surgidas o para personas cuyos reclamos de nobleza eran precarios. ${ }^{27}$ A pesar de ser imprescindible, la concesión real del hábito no era en sí suficiente para que el beneficiario fuera admitido como caballero. Como candidato a la Orden de Santiago, don José de Calatayud tuvo primero que someterse a una investigación extensiva, en que la prueba más importante era la genealógica. Para satisfacer los criterios de la orden, se le exigía demostrar mediante evidencia documental o por declaraciones juradas de testigos competentes que tanto él como sus dos padres y sus cuatro abuelos, habían sido reconocidos como hidalgos y Cristianos Viejos, que ninguno de ellos había ejercido oficios viles y que ninguno había sido penitenciado por el Santo Oficio de la Inquisición. La ilegitimidad en sí no constituía un obstáculo a las pretensiones del aspirante, pero si existía la misma en cualquiera de las tres generaciones abarcadas por el proceso investigador, era forzoso presentar evidencia de que la persona afectada llenaba los requisitos de reconocerse como "hijo natural", es decir, que al momento de su nacimiento sus padres eran ambos solteros y sin impedimento legal a su casamiento. $^{28}$

En 1672 don José de Calatayud y Castillo declaraba que si no puso en marcha inmediatamente el proceso descrito arriba, fue por las demandas de su nuevo puesto militar. Sin embargo, después de su llegada en La Habana en 1665 poco a poco se iba integrando en la élite isleña, casándose en 1669 con doña Juana de Loza Miranda, hija del capitán Ignacio de Loza Osorio, otro oficial del regimiento cubano. En ese momento la influencia de la familia Loza en la sociedad habanera parece haberse encontrado en subida, por lo que el capitán Ignacio seguramente hubiera visto con aprobación una alianza matrimonial con un colega militar cuyo padre había sido consejero de Indias y quien de su propia parte era aspirante a caballero de

\footnotetext{
${ }^{27}$ L. P. Wright, “The Military Orders in Sixteenth and Seventeenth Century Spanish Society: The Institutional Embodiment of a Historical Tradition”, Past and Present, núm. 43 (mayo de 1969), 34-70.

${ }^{28}$ Resumen de los criterios más importantes basado en el interrogatorio impreso que aparece a la cabeza del expediente de d. José de Calatayud y Castillo, 1674, AHN, Ordenes Militares 1385, sin foliar.
} 
Santiago. ${ }^{29}$ A todas luces fue precisamente a partir de su casamiento que don José de Calatayud empezó a perseguir en serio los pasos necesarios para ser recibido en la orden. En este proceso el hecho de residir en La Habana constituía una gran desventaja. Por falta de acceso directo a los testigos y documentos que se encontraban en Guatemala, para no decir los que eran disponibles solamente en España, el único modo de efectuar el trámite era por medio de agentes. Tan temprano como 1669, los parientes de don José en Guatemala, entre ellos su propia madre doña Bárbara del Castillo, se ocupaban en la recolección de testimonios de documentos y de las declaraciones de testigos. Como ya se ha visto, en 1672 Calatayud nombró a su cuñado don Gregorio Altamirano Portocarrero como su poderhabiente para gestionar en su nombre en Madrid y otros lugares en España. ${ }^{30}$

Como esposo de la heredera del mayorazgo Calatayud, don Gregorio Altamirano asumió el papel de patriarca de la familia, facilitado por su posición como integrante del Consejo de Hacienda y como caballero él mismo de la Orden de Santiago. ${ }^{31}$ En dicha capacidad, Altamirano proporcionaba a don José de Calatayud la protección y el patrocinio que antes había tenido de su padre. Para el efecto de la solicitud de ingresar como caballero de Santiago, don Gregorio se encargó de organizar las pruebas documentales para el uso del equipo investigador designado por el Consejo de Ordenes, la entidad que bajo la monarquía consolidada del siglo XVII gobernaba todas las órdenes caballerescas de Castilla.

En teoría no debía de haber sido difícil documentar la elegibilidad de don José de Calatayud según los criterios de la Orden de Santiago. La familia de su padre era bien conocida, tanto en la corte como en Valladolid, y tanto su padre como el hermano de éste habían sido también caballeros de Santiago. ${ }^{32}$ Por el lado maternal don José pertenecía a una estirpe destacada cuya presencia en Indias remontaba a la época de la conquista. Su bisabuelo era el renombrado Bernal Díaz del Castillo, quien pasó al Nuevo Mundo en 1514 como compañero de Pedrarias Dávila y luego prestó servicio bajo Fernando Cortés en la conquista de México, para después asentarse en Guatemala. Su relato a primera mano de sus aventuras en México, la

\footnotetext{
${ }^{29}$ Francisco Javier de Santa Cruz y Mallén, conde de San Juan de Jaruco y Santa Cruz de Mopox, Historia de familias cubanas, 9 tomos (La Habana: Editorial Hércules, 1940-1950; Miami: Ediciones Universal, 1985-1988), VIII, 212.

${ }^{30}$ Exp. d. José de Calatayud y Castillo, 1672, AHN, Ordenes Militares, expedientillos 4264; exp. d. José de Calatayud y Castillo, 1674, AHN, Ordenes Militares 1385, fol. 15.

${ }^{31}$ Un breve bosquejo biográfico de Altamirano aparece en, de Joseph Antonio Alvarez y Baena, Hijos de Madrid: ilustres en santidad, dignidades, armas, ciencias y artes, 4 tomos (Madrid: B. Cano, 1789-1791), II, 378-379.

${ }^{32}$ Exp. d. José de Calatayud y Castillo, 1674, AHN, Ordenes Militares 1385, fol. 26v-56.
} 
Historia verdadera de la conquista de la Nueva España, fue publicado por primera vez en Madrid in 1632 y es considerado hoy en día como un clásico de la literatura hispánica. Entre sus antepasados contaba Calatayud a otros personajes ilustres también, entre ellos el conquistador Bartolomé Becerra y un oidor de la audiencia de Guatemala de nombre de Pedro Ruiz de Corral. $^{33}$

Aunque fuera efectivamente ocultado (y por lo tanto es dudoso que pudiera haber jugado un papel en los eventos que aquí se narran), cabe mencionar la existencia en el caso de don José de Calatayud y Castillo de por lo menos un hecho incómodo. A pesar de lo afirmado por todas las partes cuyas declaraciones constan en el expediente sobre su ingreso en la Orden de Santiago, la verdad es que en el sentido más estricto don José no llenaba el requisito principal para ser considerado un "hijo natural", porque en el momento de su nacimiento su padre ya estaba casado-aunque fuera por poder-con la joven guayaquileña doña María Magdalena de Castro. Prueba de esto son las escrituras sacadas en esas fechas en que don Antonio de Calatayud refiere a doña María Magdalena como a su esposa y al padre de ésta, Toribio de Castro, como a su suegro. ${ }^{34}$ Si fuera público, el hecho de ser Calatayud el producto de una relación adúltera podría haber bloqueado su recepción como caballero. Sin embargo, después de tanto tiempo, la probabilidad es que no hubiese nadie todavía vivo que supiese de este posible impedimento y que ni el mismo don José estuviese enterado de él. Una excepción podría haber sido la propia doña Bárbara del Castillo, pero si ella sabía no tenía ningún motivo para declararlo y jamás lo hizo. Es probable por lo tanto, que don Gregorio Altamirano y los otros agentes que gestionaban en España la candidatura de don José de Calatayud ignoraran el único hecho verdaderamente capaz de obstaculizar su aceptación como caballero de la Orden de Santiago. En tal caso, la pregunta que el historiador enfrenta es por qué dependieron tan extensivamente de testimonios y documentos falsos, porque es cierto que esto lo hicieron.

Aun sin tener en cuenta el posible adulterio de parte de los padres de don José de Calatayud, todavía era necesario enfrentar la cuestión de la ilegitimidad, la cual no se negaba ni se podía negar. El imperativo al respecto era establecer sin posibilidad de contradicción que el aspirante cumplía con los criterios necesarios para clasificarse como hijo natural. Para dicho efecto hacía falta que los testigos presentados en el proceso declararan sobre acontecimientos

\footnotetext{
${ }^{33}$ Aparicio, Bernal Díaz, 25-26.

${ }^{34}$ Extractos de escrituras públicas, comp. de Juan José Falla, 4 tomos hasta la fecha (Guatemala: Editorial Amigos del País, 1994- ), I, 278; III, 322.
} 
que habían ocurrido hacía medio siglo y en una provincia donde la mayoría de ellos jamás había puesto pié. Aunque pueda parecer poco probable, consta en el expediente sobre la materia que se presentó testigo tras testigo, cada uno de los cuales afirmó bajo juramento de decir verdad lo siguiente: que al tiempo de nacer don José ambos de sus padres eran solteros y sin impedimento de casarse; que su madre doña Bárbara del Castillo aceptó tener relaciones sexuales con el oidor don Antonio de Calatayud solamente porque éste le había prometido matrimonio; que el único motivo por no haberse casado era la ley que prohibía que los oidores contrajesen matrimonio con mujeres nacidas en las provincias sobre las que ejercían jurisdicción; y, por último, que el oidor se casó con otra mujer sólo después del nacimiento del pretendiente. Ninguno de estos testigos reclamó tener conocimiento directo de estos supuestos hechos. Al contrario, todos dijeron declarar únicamente lo que habían oído contar como "público y notorio”. Posiblemente no estuvieran conscientes de que estaban dando testimonios falsos, pero seguramente se daban cuenta de que afirmaban como hechos cosas de las que no tenían ningún conocimiento propio. ${ }^{35}$

Además de las circunstancias de su nacimiento, el expediente sobre los antecedentes de don José de Calatayud contiene evidencia inventada respecto a sus abuelos maternos, Pedro del Castillo Becerra y doña Jacoba del Valle Corral. Testigos que decían haberlos conocido afirmaron que eran naturales de Medina del Campo, lugar de nacimiento de Bernal Díaz, a pesar de haber nacido los dos en Guatemala. ${ }^{36}$ Esta equivocación posiblemente se deba al mismo don José, quien sometió una genealogía errónea al Consejo de Ordenes. ${ }^{37}$ Tal error de su parte sería entendible, ya que cuando fue separado de la familia de su madre todavía era muy joven. Sin embargo, lo de los testigos es otra cosa, porque es evidente que alguien les había convencido a declarar cosas que no eran ciertas. Además de las declaraciones sobornadas, Altamirano entregó documentos que decía que eran las partidas de bautismo de Pedro del Castillo Becerra y de doña Jacoba del Valle Corral. Los encargados de la investigación aceptaron estos papeles como auténticos, pero es cierto que no lo eran. ${ }^{38}$

\footnotetext{
${ }^{35}$ Exp. d. José de Calatayud y Castillo, 1674, AHN, Ordenes Militares 1385, fol. 2-13, 24-33v.

${ }^{36}$ Exp. d. José de Calatayud y Castillo, 1674, AHN, Ordenes Militares 1385, fol. 58, 60-60v.

${ }^{37}$ Exp. d. José de Calatayud y Castillo, 1672, AHN, Ordenes Militares, expedientillos 4264. Calatayud, o tal vez alguno de sus agentes, puede también haberse engañado por un documento de Pedro del Castillo, en que éste identifica a su padre Bernal Díaz del Castillo como natural de Medina del Campo, pero la oración en cuestión es tan replegada que no sería difícil que un lector poco informado llegara a la conclusión de que no se refiriera a Bernal, sino al propio Pedro. Méritos de Pedro del Castillo Becerra, 1613, AGI, Patronato 86, no. 3, ramo 3.

${ }^{38}$ El reclamo de ser Medina del Campo el lugar de nacimiento de doña Jacoba se contradice entre otras cosas por la existencia de una partida de bautismo en Guatemala cuya autenticidad es innegable. Parroquia del Sagrario, Libro 1 de bautismos de españoles, 1577-1612, fol. 40v, AHAG. No existe tal documento para Pedro del Castillo,
} 
Una falsedad aun más atrevida fue la presentación de un documento que según reclamaba don Gregorio Altamirano, era el último testamento de Bernal Díaz del Castillo, bisabuelo de don José de Calatayud. ${ }^{39}$ De ser auténtico, tal documento constituiría un descubrimiento de mayor significado histórico, porque hasta la fecha ningún investigador ha afirmado encontrar un testamento del renombrado conquistador e historiador. ${ }^{40}$ Fuera del hecho de que el pretendido testamento está fechado en Medina del Campo en 1575, año en que se puede documentar la presencia del anciano conquistador en Guatemala, el supuesto testador se refiere a sí mismo como Bernal del Castillo, una forma de su nombre que Bernal Díaz jamás utilizó. ${ }^{41}$ Otra incongruidad es que el Bernal del Castillo del texto identifica como su padre a un tal Rodrigo de Castillo, mientras que en toda otra fuente conocida, inclusive la propia Historia verdadera, el verdadero conquistador afirma que es hijo de Francisco Díaz del Castillo, conocido como “el Galán”. ${ }^{42}$ Cabe mencionar además que en el documento en cuestión el hijo de Bernal Díaz y abuelo de don José de Calatayud, aparece como don Pedro del Castillo, mientras que el verdadero Pedro jamás se asignó el título “don” y tampoco lo trataban así sus contemporáneos. ${ }^{43}$ Finalmente, en el testamento falsificado Pedro del Castillo es identificado como único heredero de Bernal, cuando la verdad es que tenía varios hermanos y hermanas. ${ }^{44}$ El autor desconocido de este fraude puede haber decidido ocultar la existencia de los otros hijos porque no sabía sus nombres, o sencillamente porque no vio la necesidad de documentar sino la línea directa de ascendencia de don José de Calatayud. También es posible que la fuente de este error fuera el mismo Pedro del Castillo quien en 1613 declaró ser el único hijo de Bernal Díaz todavía vivo. ${ }^{45}$

probablemente porque la fecha de su nacimiento antecede la de los libros sobrevivientes. Como consecuencia, Aparicio, Bernal Díaz. 25-26, quien aparentemente tuvo acceso directo o indirecto a la genealogía sometida por don José de Calatayud, se permitió aceptar que Pedro hubiera nacido en Medina del Campo, aunque no así en el caso de su mujer. Los movimientos de Bernal Díaz en las últimas décadas de su vida son más o menos bien documentados y no hay evidencia de que él y su esposa estuvieran en España en 1567, como tendría que ser el caso para que Pedro del Castillo naciera en Medina del Campo en aquel año. Cerwin, Bernal Díaz, 183-185, 192.

${ }^{39}$ Exp. d. José de Calatayud y Castillo, 1674, AHN, Ordenes Militares 1385, fol. 15v-16.

${ }^{40}$ Para un listado de los documentos conocidos de Bernal Díaz, véanse de Henry R. Wagner, "Notes on Writings By and About Bernal Díaz del Castillo”, Hispanic American Historical Review, XXV, núm. 2 (mayo de 1945), 199211; y de Carmelo Sáenz de Santamaría, "Un documento inédito sobre Bernal Díaz del Castillo: la probanza de su nieto, don Tomás Díaz del Castillo”, Revista de Indias, XXI, núm.83 (marzo de 1961), 159-182.

${ }^{41}$ Sáenz de Santamaría, "Documento inédito”, 161-162.

42 Aparicio, Bernal Díaz, 9.

${ }^{43}$ Esta afirmación se verifica en muchos documentos, notablemente en Méritos de Pedro del Castillo Becerra, 1613, AGI, Patronato 86, núm. 3, ramo 3.

${ }^{44}$ Aparicio, Bernal Díaz, 12-14.

${ }^{45}$ Méritos de Pedro del Castillo Becerra, 1613, AGI, Patronato 86, núm. 3 ramo 3. 
No podía haber sorprendido a los contemporáneos de don José de Calatayud y Castillo el que mucho del contenido de su expediente hubiera sido inventado para la ocasión. Hay indicios de que el cohecho de los testigos fuera una práctica común de parte de los aspirantes a las órdenes militares. ${ }^{46}$ Hasta existían autoridades quienes argumentaban que, puesto que ni el honor ni la nobleza eran calidades intrínsecas del individuo, sino construcciones sociales, los hechos vergonzosos no se debían tener en contra de una persona, a menos que fueran públicamente conocidos. Según tal raciocinio, un testigo quien poseyera conocimiento particular de un "defecto" o "mancha” no estaba bajo ninguna obligación de hacerlo público. Era posible hasta sostener el que tal testigo estuviera obligado a testificar falsamente antes de revelar la existencia de un hecho incómodo que de otro modo no se conocía. ${ }^{47}$ Debido a que su ilegitimidad era públicamente reconocida (y presumiendo siempre que ni el mismo aspirante tenía conocimiento del posible adulterio de parte de sus padres), en el caso de don José de Calatayud no existían secretos vergonzosos de este tipo. Cabe preguntar por lo tanto, por qué don Gregorio Altamirano y los otros agentes encargados de gestionar la solicitud de ingreso sentían la necesidad de llenar el expediente con tantas mentiras y falsificaciones.

La respuesta a esta cuestión la debemos buscar en la naturaleza del mismo proceso burocrático visto en el contexto tanto de los desafíos prácticos que dificultaban la realización de una encuesta a escala imperial, como de ciertas prácticas que se acostumbraban utilizar en la producción de documentos oficiales, para la cobertura de aquellas complejidades e incertidumbres que se podían presentar en la vida de cualquier persona. Bajo los procedimientos establecidos para la certificación de los candidatos a hábitos en las órdenes militares, hacía falta una investigación pormenorizada de los antecedentes del candidato y de sus padres y abuelos. Para los aspirantes nacidos en España este requisito no presentaba mayores dificultades. Sin embargo, si el candidato nació en Indias y ya no residía en la provincia de su origen, el proceso de recolectar los documentos necesarios y las declaraciones de testigos podía implicar un gasto tan excesivo de tiempo y dinero como para imposibilitar su ingreso como caballero. Para ajustarse a esta realidad, el Consejo de Ordenes permitía que las investigaciones de pretendientes americanos se pudieran realizar basándose únicamente en las declaraciones de testigos radicados en España. En el caso específico de don José de Calatayud y Castillo, esto significaba la

\footnotetext{
${ }^{46}$ Wright, “Military Orders”, 64.

${ }^{47}$ Twinam, Public Lives, 49-50.
} 
necesidad de buscar en Madrid y otros lugares cercanos a personas de la apropiada categoría social, quienes estuvieran dispuestas a afirmar bajo juramento que habían conocido a don José y a su familia en Guatemala, en Perú, o en alguna otra provincia ultramarina. De los muchos testigos presentados durante la investigación, sólo uno nació en Guatemala y éste era todavía niño en los años en que dijo haber conocido a Calatayud. ${ }^{48}$ Los otros declararon que se habían encontrado con don José o con su padre don Antonio de Calatayud en alguna que otra parte del Imperio. Desde el punto de vista de don Gregorio Altamirano, no podía importar mucho el tener ninguno de estos declarantes conocimiento de primera mano, por ejemplo de la relación que existía entre los padres de don José. Importaba solamente que se conformaran a repetir una versión de los hechos determinada de antemano.

Lo mismo se puede decir de los testigos en Medina del Campo quienes reclamaban tener conocimiento de los abuelos de Calatayud, cuando obviamente no tenían tal cosa. Al preparar su testimonio, Altamirano se aprovechó de los datos limitados que don José le había proporcionado. Aunque no los pudiera confirmar independientemente con pruebas documentales sacadas en Guatemala, es posible que don Gregorio creyera que los citados datos fueran ciertos. Es posible también que los testigos que reclutaba actuaran bajo la misma presuposición. Sin embargo, es igualmente posible que todas las partes operaran bajo otra presuposición enteramente diferente: eso es, que sin importar si las declaraciones fueran verdaderas o no, no dañaban a nadie, mientras que eran suficientes para llenar los requisitos de la Orden de Santiago, el cual al final de las cuentas era el único objetivo del proceso. Sería encantado pensar que el aprovechamiento de los documentos falsificados y los testigos sobornados fuera algo fuera de lo ordinario. Al contrario, parece haber sido práctica común que los escribanos amoldaran los documentos escritos de tal manera que se llenasen las necesidades de sus clientes, especialmente en aquellos casos en que la verdad era demasiado complicada para representar con facilidad. Conocido por algunas historiadores bajo el rubro de la "verdad notarial”, ${ }^{49}$ el resultado de tales prácticas es un cuerpo documental, que a pesar de haber servido admirablemente los fines de sus creadores, ofrece múltiples peligros a los historiadores que intentamos utilizarlo como base de nuestras investigaciones.

\footnotetext{
${ }^{48}$ Exp. d. José de Calatayud y Castillo, 1674, AHN, Ordenes Militares 1385, fol. 9-9v.

${ }^{49}$ Burns, "Notaries, Truth, and Consequences.”
} 
Al final de las cuentas, el registro fabricado por los agentes de don José de Calatayud y Castillo tuvo el efecto deseado. La solicitud de éste de incorporarse en la Orden de Santiago fue aprobada y el título se emitió en 1675. Persona de influencia en la sociedad colonial cubana, don José permaneció asentado en La Habana hasta sorprenderle la muerte el 24 de septiembre de 1696. ${ }^{50}$ Como sin duda hacían muchos otros, dejó detrás de sí un legado documental en que los historiadores podemos confiar solamente a nuestro propio riesgo. A primera vista los expedientes de las investigaciones extensivas tales como aquellos formados como parte de los trámites necesarios para vestir los hábitos de las órdenes militares, parecen ser fuentes históricas de gran valor, ofreciendo acceso a datos biográficos y genealógicos que de otro modo serían difíciles si no imposibles de encontrar. Parecen contener también declaraciones verbales y reproducciones textuales de documentos que no se hallan en ninguna otra parte. Desafortunadamente, como demuestra el caso de don José de Calatayud y Castillo, pueden también estar llenos de mentiras.

${ }^{50}$ D. Diego de Córdoba Laso de la Vega, La Habana, 28 de octubre de 1696, AGI, Santo Domingo 113, ramo 4, núm. 35B. 